\title{
PERCEPTIONS OF PHYSICIANS AND ALLIED HEALTH CARE WORKERS OF PHARMACISTS' ROLE IN CARE OPTIMIZATION FOR SCHIZOPHRENIC PATIENTS AT FEDERAL NEURO-PSYCHIATRIC HOSPITAL MAIDUGURI, NORTH-EASTERN NIGERIA
}

\author{
H YUSUF ${ }^{1}$, A GIWA $^{2}$, S MOHAMMED ${ }^{2}$, SN AGUYE ABDU ${ }^{2}$, FM DUNGUS $^{1}$, A SANI $^{3}, \mathrm{~F}_{\text {ASHEMI }}$ ASH $^{4}$
}

\begin{abstract}
Introduction: In clinical practice, it is required that a profession not only clearly describe their own roles and responsibilities to other professionals but should also be aware of other professions' roles in relation to their own. The objective of this study was to assess the perceptions of physicians and allied health care workers (Other health care professionals) of the roles of pharmacists in optimizing care for schizophrenic patients.
\end{abstract}

\begin{abstract}
Methods: A self-administered 17-item validated questionnaire was distributed to 120 health care professionals working at Federal Neuro-Psychiatric Hospital Maiduguri from September to October 2016. Results obtained were analysed using Chi-square test.

Results: Health care professionals mostly had positive perceptions with a statistically significant difference $(P<0.05)$ across all assessed items. However, competent and knowledge of the pharmacists accounting for 93 (83.8\%), involvement of the pharmacist in patient care accounting for 91(82\%) and reassuring patients to improve quality of life accounting for 98(88.3\%) had the highest number of health care professionals with positive perceptions while documenting patient care, monitoring and reemphasizing physicians instructions had the lowest accounting for 69 (62.2\%), 74(66.7\%) and 74 (66.7\%) respectively in the different sections.
\end{abstract}

Conclusions: The health care professionals surveyed mostly had positive perceptions. Thus, pharmacists can leverage on this to meet their roles in optimizing care for schizophrenic patients.

Keywords: Perceptions, Health care professionals, Pharmacists' roles, Schizophrenic patients, Nigeria.

Received: 03 September 2018

Accepted: 05 November 2018

DOI: https://doi.org/10.3329/bjmed.v30i1.39918

\section{Introduction}

In recent times, Patients have complex health needs that require a multidisciplinary team to address issues regarding their general health. ${ }^{1}$ Collaborative interactions involve a blending of professional culture and this is achieved by sharing skills and knowledge to improve the quality of patient care. ${ }^{2}$

Inter-professional collaboration can be challenging and barriers such as role identification and classification of expectations continue to be a problem in the delivery of health care. $^{3}$ Good team work relies on a joint understanding of one's own as well as other team members' competence or knowledge and skills ${ }^{4}$. In clinical practice, this requires that a profession not only clearly describe their own roles and responsibilities to other professionals but should also be aware of other professions' roles in relation to their own. ${ }^{4}$

Pharmaceutical care (PC) is defined as the responsible provision of drug therapy for the purpose of achieving definite outcomes that improve patient's quality of life.

1. Department of Clinical Pharmacy and Pharmacy Administration, University of Maiduguri, Maiduguri, Nigeria.

2. Department of Clinical Pharmacy and Pharmacy Practice, Ahmadu Bello University, Zaria, Kaduna state, Nigeria.

3. Department of Pharmaceutical services, Federal Neuro Psychiatric Hospital Maiduguri, Maiduguri, Nigeria.

4. Department of Pharmacology and Toxicology, University of Maiduguri, Maiduguri, Nigeria.

Address of correspondence : Hadiza Yusuf, Department of Clinical Pharmacy and Pharmacy Administration, University of Maiduguri, Maiduguri, Borno State, Nigeria, Email: hadizayusuf3@gmail.com Tel: 07036901906, 09085606817

Bangladesh J Medicine 2019; 30 : 19-23 
These outcomes can include: cure of a disease, elimination or reduction of patients' symptoms and arresting or slowing of the disease process or symptoms. ${ }^{5}$ It often involves a process through which the pharmacist works with both patient(s) and other health care professionals (HCP's) in designing, implementing, and monitoring therapeutic procedures that should produce specific positive outcomes for the patient. $^{5}$

Issues like the availability of a wide variety of drug treatment options, frequent occurrence of side effects and low antipsychotic medication compliance, give pharmacists important roles to play in the overall successful treatment of patients with schizophrenia ${ }^{6}$. Effective inter-professional cooperation between HCP's and a positive perception of roles is necessary to achieve this. Therefore this study aimed at evaluating the perceptions of physicians and allied health care workers (other health care professionals) of pharmacists' roles in optimizing care for schizophrenic patients.

\section{Materials and Methods}

\section{Study design and setting}

A descriptive cross sectional study was carried out between September and November 2016 at the Federal Neuro- Psychiatric Hospital (FNPH) Maiduguri, located in the North- Eastern part of Nigeria. Informed consent was obtained from individual participants and overall ethical approval from the hospitals' ethics committee was also obtained on $4^{\text {th }}$ August 2016.

Sample size estimation and sampling procedure

The total population of HCP's during the period of this study was estimated to be 140 (physicians- $n=25$, Nurses- $n=85$, medical lab scientists- $n=14$ radiologists$n=2$, radiographers $-n=10$ and psychologists $n=4$ ).

Based on this, the study sample size of 120 was obtained using the formula reported by Kenneth et.al. ${ }^{7}$

$\mathrm{n}=\mathrm{N} / 1+\mathrm{N}(\mathrm{e})^{2}$

$\mathrm{n}=140 / 1+140(0.05)^{2}$

$\mathrm{n}=140 / 1.35$

$\mathrm{n}=103.7$

$\mathrm{n}=104$

$\mathrm{n}=$ desired sample size

$\mathrm{N}=$ estimated size of the study population

$\mathrm{e}=$ margin of error $(0.05)$

Adding $15 \%$ of this to take care of attrition;

$15 / 100) \times 104$

$0.15 \times 104=15.6$

$15.6+104=119.6$
Therefore the number of other health care professionals to be recruited was estimated to be 120 .

Proportionate quota sampling of this population was then employed and a total of 22 physicians, 70 nurses, 12 medical lab scientists, 2 radiologists, 10 radiographers and 4 psychologists were included in this research. The purpose of the research and confidentiality of information to be provided was explained to each health care professional that was approached to participate. HCP's who consented to participate were then given a period of seven days to complete the pretested, self-administered structured questionnaire.

\section{Survey instrument}

A 17-item, self-administered questionnaire utilizing a five point likert scale (strongly disagree, disagree, undecided, agree and strongly agree) was used for the survey. The questionnaire items were adapted from a previous study ${ }^{8}$, and then modified. The instrument was then reviewed by a clinical pharmacist for face validity and consequently pretested on 12 health care professionals. Appropriate adjustments were then made as necessary. The instrument contained 4 sections. Section one contained questions that assessed socio-demographic characteristics of the respondents including gender, age etc. While the other sections included questions assessing perceptions of the healthcare professionals of Pharmacists' roles in specific areas/domains.

\section{Data analysis}

Respondents that agreed or strongly agreed on each of the items were considered to have positive perceptions while those that disagreed or strongly disagreed were considered to have

negative perceptions. The Chi - square test was used to find significant differences between these groups. $\mathrm{P}$ values d" 0.05 were considered significant. Statistical package for social science (SPSS) version 20 (SPSS Inc, Chicago, Illinois, USA) was used for statistical analysis. Data is presented in frequency distribution tables.

\section{Results}

Out of the 120 questionnaires administered to the HCP's, 111 were retrieved giving a $92.5 \%$ response rate. Out of the 111 HCP's, 72 (64.90\%) were males while 39 (35.10\%) were females. Fifty four (48.65\%), out of the 111 HCP's fell within the age range of 3039 . Forty nine $(44.14 \%)$ had experience of $<=5$ years (Table I). 
BJM Vol. 30 No. 1 Perceptions of Physicians and Allied Health Care Workers of Pharmacists' Role In Care Optimization

Table-I

Distribution of health care professionals according to their socio demographic characteristics

\begin{tabular}{lcc}
\hline Variables & $\begin{array}{c}\text { Distribution } \\
(\mathrm{n}=111)\end{array}$ & $\begin{array}{c}\text { Percentage } \\
\text { distribution (\%) }\end{array}$ \\
\hline Sex & 72 & 64.90 \\
Male & 39 & 35.10 \\
Female & & \\
Age & 34 & 30.63 \\
$<30$ & 54 & 48.65 \\
30-39 & 23 & 20.72 \\
$>=40$ & & \\
Profession & 21 & 18.90 \\
Physician & 66 & 59.50 \\
Nurse & 11 & 9.90 \\
Medical lab. Scientist & 1 & 0.90 \\
Radiologists & 9 & 8.10 \\
Radiographers & 3 & 2.70 \\
Psychologists & & \\
Years of experience & 49 & 44.14 \\
$<=5$ & 36 & 32.43 \\
6-10 & 26 & 23.43 \\
>10 & & \\
\hline
\end{tabular}

In the areas of patient counselling, source of drug literature, patient supplies, Pharmacists' competence and documentation of care, health care professionals mostly had positive perceptions with a statistically significant difference $(\mathrm{P}<0.05)$ across all assessed items. However, competence and knowledge of the pharmacists had the highest number of respondents with positive perceptions accounting for 93(88.8\%), while documenting patient care and evaluating outcomes had the lowest number of respondents with positive perceptions accounting for $69(62.2 \%)$ out of 111 respondents (Table II).

In the area of therapeutic plan development, implementation and monitoring, HCP's mostly had positive perceptions with a statistically significant difference $(\mathrm{P}<0.05)$ across all assessed items. Involvement of the pharmacists in patient care had the highest number of respondents with positive perceptions accounting for 91 (82\%) out of 111 , while monitoring adherence, efficacy and adverse drug reactions had the lowest number of respondents with positive perceptions accounting for 74 (66.7\%) out of 111 respondents (Table III).

Table-II

Perceptions of pharmacist roles in the areas of patient counselling, source of drug literature, patient supplies, Pharmacists' competence and documenting care

\begin{tabular}{|c|c|c|c|c|c|c|}
\hline \multirow[b]{2}{*}{ Element } & \multirow{2}{*}{$\begin{array}{l}\text { Neg } \\
\mathrm{p}(\%)\end{array}$} & \multirow{2}{*}{$\begin{array}{l}\text { Und } \\
(\%)\end{array}$} & \multirow{2}{*}{$\begin{array}{l}\text { Pos } \\
\mathrm{p}(\%)\end{array}$} & \multicolumn{3}{|c|}{ Test statistics } \\
\hline & & & & $\chi^{2}$ & $P$ value & Df \\
\hline $\begin{array}{l}\text { Patient counselling on usage, side effects and } \\
\text { interactions of antipsychotics }\end{array}$ & $11(9.9)$ & $14(12.6)$ & $86(77.5)$ & 97.4 & $\mathrm{P}<0.05$ & 2 \\
\hline Source of current and up to date drug literature & $11(9.9)$ & $14(12.6)$ & $86(77.5)$ & 97.4 & $\mathrm{P}<0.05$ & 2 \\
\hline $\begin{array}{l}\text { Provide adequate patient supplies, information } \\
\text { and knowledge }\end{array}$ & $15(13.5)$ & $10(9.0)$ & $86(77.5)$ & 97.4 & $\mathrm{P}<0.05$ & 2 \\
\hline Competent and knowledgeable & $4(3.6)$ & 14 (12.6) & 93 (83.8) & 123.4 & $\mathrm{P}<0.05$ & 2 \\
\hline Documenting patient care and evaluating outcomes & $20(18.0)$ & $22(19.8)$ & $69(62.2)$ & 41.5 & $\mathrm{P}<0.05$ & 2 \\
\hline
\end{tabular}

Neg $p=$ Negative perception, Und $=$ Undecided, Pos $p=$ Positive perception

Table-III

Perceptions of pharmacist roles in the areas of therapeutic plan development, implementation and monitoring.

\begin{tabular}{|c|c|c|c|c|c|c|}
\hline \multirow[b]{2}{*}{ Element } & \multirow{2}{*}{$\begin{array}{l}\text { Neg } \\
\mathrm{p}(\%)\end{array}$} & \multirow{2}{*}{$\begin{array}{l}\text { Und } \\
(\%)\end{array}$} & \multirow{2}{*}{$\begin{array}{l}\text { Pos } \\
\mathrm{p}(\%)\end{array}$} & \multicolumn{3}{|c|}{ Test statistics } \\
\hline & & & & $\chi^{2}$ & $P$ value & Df \\
\hline Developing therapeuticcare plan & $19(17.1)$ & $15(13.5)$ & $77(69.4)$ & 65.0 & $\mathrm{P}<0.05$ & 2 \\
\hline Access to patient data & $10(9.0)$ & $21(18.9)$ & $80(72.1)$ & 76.5 & $\mathrm{P}<0.05$ & 2 \\
\hline Involvement in Schizophrenicpatients drug regimen & $16(14.4)$ & $16(14.4)$ & $79(71.2)$ & 71.5 & $\mathrm{P}<0.05$ & 2 \\
\hline $\begin{array}{l}\text { Ensuring antipsychotic drug safety and therapeutic } \\
\text { appropriateness }\end{array}$ & $11(9.9)$ & $15(13.5)$ & $85(76.6)$ & 93.6 & $\mathrm{P}<0.05$ & 2 \\
\hline Involvement in patient care & $9(8.1)$ & 11 (9.9) & $91(82.0)$ & 18.2 & $\mathrm{P}<0.05$ & 2 \\
\hline $\begin{array}{l}\text { Assessment, identification and resolution of drug } \\
\text { therapy problems }\end{array}$ & $13(11.7)$ & $14(12.6)$ & $84(75.7)$ & 89.5 & $\mathrm{P}<0.05$ & 2 \\
\hline $\begin{array}{l}\text { Monitoring adherence, efficacy and adverse } \\
\text { drug reactions }\end{array}$ & $20(18.0)$ & 17 (15.3) & 74 (66.7) & 55.6 & $\mathrm{P}<0.05$ & 2 \\
\hline
\end{tabular}

Neg $\mathrm{p}=$ Negative perception, Und $=$ Undecided, Pos $\mathrm{p}=$ Positive perception 
Table-IV

Perceptions of pharmacist roles in the area of improving patients' quality of life

\begin{tabular}{|c|c|c|c|c|c|c|}
\hline \multirow[b]{2}{*}{ Element } & \multirow{2}{*}{$\begin{array}{l}\text { Neg } \\
\mathrm{p}(\%)\end{array}$} & \multirow{2}{*}{$\begin{array}{l}\text { Und } \\
(\%)\end{array}$} & \multirow{2}{*}{$\begin{array}{l}\text { Pos } \\
\mathrm{p}(\%)\end{array}$} & \multicolumn{3}{|c|}{ Test statistics } \\
\hline & & & & $c^{2}$ & $\mathrm{P}$ value & Df \\
\hline $\begin{array}{l}\text { Ensuring schizophrenicpatients return for } \\
\text { medication refill or review }\end{array}$ & $15(13.5)$ & $11(9.9)$ & $85(76.6)$ & 93.6 & $\mathrm{P}<0.05$ & 2 \\
\hline Ensuring antipsychoticAvailability & $6(5.4)$ & $24(21.6)$ & $81(73.0)$ & 82.8 & $\mathrm{P}<0.05$ & 2 \\
\hline $\begin{array}{l}\text { Monitoring patients compliance to antipsychotic } \\
\text { therapy }\end{array}$ & $13(11.7)$ & $19(17.1)$ & $79(71.2)$ & 72.0 & $\mathrm{P}<0.05$ & 2 \\
\hline Reassuring Patients to improve quality of life & $5(4.5)$ & $8(7.2)$ & $98(88.3)$ & 150.9 & $\mathrm{P}<0.05$ & 2 \\
\hline Re-emphasizing Physicians'Instructions & $21(18.9)$ & $15(13.5)$ & $75(67.6)$ & 59.0 & $\mathrm{P}<0.05$ & 2 \\
\hline
\end{tabular}

Neg $\mathrm{p}=$ Negative perception, Und $=$ Undecided, Pos $\mathrm{p}=$ Positive perception

In the area of improving patients' quality of life, HCP's mostly had positive perceptions with a statistical significant difference $(\mathrm{P}<0.05)$ across all assessed items. Reassuring patients to improve quality of life had the highest number of respondents with positive perceptions accounting for 98 (88.3\%) out of 111 , while re-emphasizing physicians' instructions had the lowest number of respondents with positive perceptions accounting for $75(67.6 \%)$ out of 111 respondents (Table IV).

\section{Discussion}

The roles of pharmacists must be positively perceived by other HCP's before effective inter-professional collaboration can take place. As earlier stated, pharmaceutical care cannot exist in isolation from other health care services ${ }^{9}$ and must be provided in collaboration with patients and other health care professionals. Majority of the HCP's perceived pharmacists as playing key roles in the area of patient counselling, as sources of drug literature, patient supplies and in documentation of care. This is similar to previous findings where the role of pharmacists for HIV / AIDS patients was positively perceived by HCP's. ${ }^{8}$ This also reflects the practice requirements of pharmaceutical care as stated by United State Agency for International Development (USAID) that pharmacists should provide accurate and comprehensive information about drugs to both patients and HCP's as appropriate ${ }^{10}$. Professional competence and knowledge of the pharmacists had a very high number of health care professionals with positive perceptions when compared to other items in this section. Pharmacists can thus help to facilitate improved prescribing and medicines management by working closely with HCP's. ${ }^{11}$ Documenting patient care and evaluating outcome had the lowest number of HCP's with positive perceptions in this section. It has been discovered that while pharmacists recognise the importance of documenting relevant issues, they rarely do so in practice and preferred to use oral communication or temporary adhesive notes instead. ${ }^{12}$

The HCP's also positively perceived the roles of pharmacists in therapeutic plan development and implementation, as well as monitoring and evaluation of interventions. These are important roles for pharmacists because of the range of side effects associated with antipsychotic drug therapy. A previous study has shown that pharmacists can assist in identifying potential risks for development of neuroleptic induced tardive dyskinesia ${ }^{13}$. The morbidity associated with neuroleptic- induced tardive dyskinesia has exposed health care providers to legal repercussions in other countries. Therefore, pharmacist interventions in this area may aid in the reduction of legal liabilities. ${ }^{13}$ Involvement of pharmacists in patient care was highly perceived by health care professionals. Previous study has proved that pharmacists' services contributed positively to patient care. ${ }^{14}$ Monitoring adherence, efficacy and adverse drug reaction had the lowest number of HCP's with positive perception. Reasons for this is not very clear and therefore merits further evaluation.

Surveyed HCP's also positively perceived the roles of pharmacists in improving patients' quality of life. Reassuring patients to improve quality of life had the highest number of health care professionals with positive perceptions in this section. A recent study has shown that pharmacists allowed patients to take more responsibility in their care and spent time explaining their treatment plan ${ }^{15}$. Re-emphasizing physicians' instructions had the lowest number of HCP's with positive perceptions in this section. Re-emphasising instruction can improve patients' adherence to antipsychotic medications. It has been proven that if 
BJM Vol. 30 No. 1 Perceptions of Physicians and Allied Health Care Workers of Pharmacists' Role In Care Optimization

adherence to first use of antipsychotic drugs is improved, chances of relapse decline and long-term prognosis can improve. ${ }^{16}$ Pharmacists are at the end of the prescribing process and are often the last health care professional with whom the patient has contact before making their medicine-taking decision. This places pharmacists in a strong position in terms of involvement in decisions about medicine taking. In schizophrenia, a well-educated and motivated pharmacist may be the ideal person to transfer the benefits of therapeutic compliance. ${ }^{17}$

\section{Conclusion}

The health care professionals surveyed in this work mostly had positive perceptions of the roles of pharmacists in optimizing care for schizophrenic patients. Pharmacists at the institution should leverage on these positive perceptions and strive to meet their roles in optimizing care for schizophrenic patients.

\section{Acknowledgement}

We wish to thank the management and staff of University of Maiduguri, Nigeria and Federal Neuro psychiatric Hospital Maiduguri, Nigeria for their immense assistance towards the realisation of this work.

\section{References}

1. Lumague M, Morgan A, Mak D, Hanna M, Kwong J, Cameron C. Interprofessional education: the student perspective. J interprof Care.2008; 20:246-53

2. Roa R. Dignity and impudence: how should medical students acquire and practice clinical skills for use with older people? Med Educ. 2003; 37:190-1.

3. Lapkin S, Lavett-Jones T, Gilligan CA. Systematic review of the effectiveness of interprofessional education in health professional program. Nurse Educ.2013; 33, 90102.

4. Drinka TJK, Clark PG. The Science and Art of interdisplinary practice, in health care team work: interdisplinary practice and teaching.Westport, CT: Auburn House.2000; 187.

5. Hepler CD and Strand LM .Opportunities and responsibilities in Pharmaceutical Care. Amer J of Hos Pharm. 1990; 47:533-43.

6. Rijcken CAW, Boelema GJ, Slooff CJ. The role of the pharmacist in the treatment of schizophrenia [internet].
2002. [cited 2017 Jan 15] Available from http:// www.rug.nl/research/portal/files/.../c1.

7. Kenneth AA, Obehi O, Dorothy ANO, Rosalyn CK, Mohammadu, AI, Paul GI et al. Health related quality of life and CD4 cells status of patients receiving Antiretroviral therapy in Nigeria. West Afri $J$ of Pharm.2012; 23 (2): 27-33.

8. Giwa A, Giwa HBF, Yakubu SI, Ajiboye WT, Abubakar D, Abe SA. Perception of other health care professionals on Pharmacists' roles in optimizing pharmaceutical care for HIV/AIDS patients in University of Maiduguri Teaching Hospital, North-Eastern Nigeria. J of Pharmacol and Tropi Therap. 20111(2) 12-16.

9. Van Mil JW, Schulz M and Tromp FJ. Pharmaceutical care, European developments in concepts, implementation, teaching and research. Pharm World Sci.2004; 6:303-311.

10. United State Agency for International Development (USAID). Launching of the pharmacy service; strengthening component of the Global HIV/AIDS initiative Nigeria. Position Paper. 2005; p. 1-15.

11. Boorman S and Cairns C. Another way forward for pharmaceutical Care: A team based Castillo. Outpatient Pharmacy Care and HIV Viral load response among patient on HAART. AIDS Care. 2000; 16 (4): 146 - 57.

12. Wendy P and Bryony DF. Pharmacists' documentation of patients' hospital health records. Issues and edu impl. 201018 (2):108-115

13. Lacro JP, Kodsi AB, Gilbert PL. Psychopharmacists' role in neuroleptic therapy, a pharmaceutical approach. J Pharm Techn . 1994; 10:164-168.

14. Posey L.M. Providing that pharmaceutical care makes a difference in community pharmacy. J Amer pharm assoc. 2003; 24:136-139

15. Maoliosa D, Kathryn K, Ross TT, Yazid NA, Charlotte A J.2017. Patient, family physician and community pharmacists' perspectives on expanded pharmacy scope of practice: a qualitative study, CMAJ Open. 2017; 5(1):205-212.

16. Power P, Elkins K, Adlard S . Analysis of the initial treatment phase of first episode psychosis. Br J Psychiatry. 1998; 172: (33) :71-76.

17. Rijcken CAW, Boelema GJ, Slooff CJ . The role of the pharmacist in the treatment of schizophrenia: a review. Submitted 2002 [internet]. Available at www.rug.nl/ research/portal/files/.../C1.pdf. 